\title{
Role of cerebrospinal fluid in differentiation of human dental pulp stem cells into neuron-like cells
}

\author{
Ghazaleh Goudarzi ${ }^{1,2}$, Hatef Ghasemi Hamidabadi ${ }^{2,3}$, Maryam Nazm Bojnordi $^{2,3}$, Azim Hedayatpour ${ }^{4}$, \\ Ali Niapour ${ }^{5}$, Maria Zahiri ${ }^{6}$, Forouzan Absalan ${ }^{7}$, Shahram Darabi ${ }^{8}$ \\ ${ }^{1}$ Department of Brain and Cognitive Sciences, Cell Science Research Center, Royan Institute for Stem Cell Biology and Technology, ACECR, Tehran, \\ ${ }^{2}$ Department of Anatomy \& Cell Biology, Faculty of Medicine, Mazandaran University of Medical Sciences, Sari, ${ }^{3}$ Immunogenetic Research Center, \\ Department of Anatomy \& Cell Biology, Faculty of Medicine, Mazandaran University of Medical Sciences, Sari, ${ }^{4}$ Department of Anatomy, School of \\ Medicine, Tehran University of Medical Sciences, Tehran, ${ }^{5}$ Research Laboratory for Embryology and Stem Cells, Department of Anatomical Sciences, \\ School of Medicine, Ardabil University of Medical Sciences, Ardabil, ${ }^{6}$ Department of Anatomical Sciences, School of Medical Sciences, Bushehr \\ University of Medical Sciences, Bushehr, ${ }^{7}$ Abadan School of Medical Sciences, Abadan, ${ }^{8}$ Cellular and Molecular Research Center, Qazvin University of \\ Medical Sciences, Qazvin, Iran
}

\begin{abstract}
Human dental pulp stem cells (hDPSCs) could be differentiated into neuron like-cells under particular microenvironments. It has been reported that a wide range of factors, presented in cerebrospinal fluid (CSF), playing part in neuronal differentiation during embryonic stages, we herein introduce a novel culture media complex to differentiate hDPSCs into neuron-like cells. The hDPSCs were initially isolated and characterized. The CSF was prepared from the Cisterna magna of 19-day-old Wistar rat embryos, embryonic cerebrospinal fluid (E-CSF). The hDPSCs were treated by $5 \%$ E-CSF for 2 days, then neurospheres were cultured in DMEM/F12 supplemented with $10^{-6} \mu \mathrm{m}$ retinoic acid (RA), glialderived neurotrophic factor and brain-derived neurotrophic factor for 6 days. The cells which were cultured in basic culture medium were considered as control group. Morphology of differentiated cells as well as process elongation were examined by an inverted microscope. In addition, the neural differentiation markers (Nestin and MAP2) were studied employing immunocytochemistry. Neuronal-like processes appeared 8 days after treatment. Neural progenitor marker (Nestin) and a mature neural marker (MAP2) were expressed in treated group. Moreover Nissl bodies were found in the cytoplasm of treated group. Taking these together, we have designed a simple protocol for generating neuron-like cells using CSF from the hDPSCs, applicable for cell therapy in several neurodegenerative disorders including Alzheimer's disease.
\end{abstract}

Key words: Human dental pulp stem cells, Cerebrospinal fluid, Cell transdifferentiation, Alzheimer

Received December 17, 2019; Revised July 13, 2020; Accepted July 30, 2020

\section{Introduction}

Degeneration of neurons is one of the features of neurode-

\footnotetext{
Corresponding author:

Hatef Ghasemi HamidabadI (iD

Department of Anatomy \& Cell Biology, Faculty of Medicine, Mazandaran University of Medical Sciences, Sari 33044756, Iran

E-mail:hatefdr@gmail.com
}

generative disease that have a major impact at quality of patient's life. Considering that this type of disorder are rapidly rising, it is important to access a strategy to disease prevention. A treatment that has recently attracted the attention of researchers is the differentiation of stem cells into neuronlike cells under specific microenvironment and transplanted them to the lesion. However, none of them cannot prevent the progression of disease. In this way, the material that seems useful is cerebrospinal fluid (CSF). CSF produced by Choroid plexus with epithelial and vascular structure. To date, the 
findings has revealed that CSF has some microenvironment which are necessary for neurogenesis such as transforming growth factor- $\beta$ (TGF- $\beta$ ), nerve growth factor (NGF), brainderived neurotrophic factor (BDNF), neurotrophin-3 (NT-3), insulin-like growth factor (IGF), hepatocyte growth factor (HGF), and basic fibroblast growth factor (b-FGF) [1]. Several research have shown the role of CSF factors on proliferation and differentiation of mesenchymal stem cells (MSCs) into neuron-like cells through the interacting by specific receptor on the cell surface. This findings suggest that the tissue microenvironment can induce the differentiation $[2,3]$. According to our previous study, we investigated the influence of CSF accompanied by retinoic acid (RA) on differentiation of MMSCs into neuron-like Cells in vitro. The results suggested that CSF accompanied RA lead to differentiation of neuron-like cells from BMSCs in vitro [4]. As well CSF by its factors such as IGFs regulates a condition that is required for maintenance of neural progenitor cells that are located in subgranular zone and subventricular zone. So, Alterations in neural stem cell homeostasis can contribute to the consequences of neurodegenerative disorder such as Alzheimer's disease $(\mathrm{AD})[5,6]$. On the other hand, the aggregation of some misfolded proteins in AD cause the neuronal death in the hippocampus $[7,8]$. However, without inductive conditions, human dental pulp stem cells (hDPSCs) can express neural progenitor marker such as Nestin and GFAP but under specific conditions, can express the post-mitotic neural marker like NeuN, which indicates their potential in neural differentiation $[9,10]$. Although hDPSCs in condition media with various molecules as inducer can differentiate into neuron-like cells, their differentiations are incomplete [9]. Nevertheless, one strategy to change the phenotype of hDPSCs into neural-like cells is to simulate of neurons using growth factors, cytokines and vitamins. Therefore, the current study focuses on the evaluation of neurogenic potential of hDPSCs using CSF and RA as inducers. These ecto-MSCs have some characteristics which make them appropriate source for use in cell therapy. For example, they are easily obtained from dental pulp tissue, high proliferation potential and they can differentiate into multiple cell lineages such as neurons in vitro [9,11]. Other factors such as RA are used for differentiation of stem cells into neuron-like cell. RA is one of the most important morphogens is involved in the early stages of central nervous system development and cause neurogenesis [12]. So, this factor can be used as a therapeutic molecule to induce regeneration of axons [13]. In this way, Sagha et al. [14] evaluated the effects of RA on stem cells and concluded that RA increased the rate of neurogenesis. Although, different factors have been investigated to differentiate MSCs into the neuron-like cells, no suitable condition has provided for this type of differentiation. We found that using CSF and RA on the hDPSCs could improve the quality of the derived neuron like-cells. Therefore, transplantation of this source of cells probably can be considered as a therapeutic approach for the neurodegenerative disease treatment.

\section{Materials and Methods}

\section{Human dental pulp stem cells extraction and cultivation}

In this experimental study, the third molar teeth without caries were collected under confirmed guidelines set by Dental Clinic of Mazandaran University of Medical Science with informed consent of the participants and in according to Helsinki Declaration. The surfaces of the teeth were cleaned by phosphate buffered saline (PBS), then the pulp tissue was gently separated and cut into small pieces under sterile conditions and enzymatically digested in digestion solution which contained the trypsin 0.25\% (Gibco, Gran Island, NY, USA) enzyme, in the next step centrifuged at $800 \mathrm{rpm}$ at $4^{\circ} \mathrm{C}$ for 5 minutes, then the supernatant was removed. The isolated cells were grown in DMEM/F12 (Gibco-Life Technologies, Invitrogen, Paisley, Scotland, UK) supplemented with 15\% fetal bovine serum (FBS; Sigma, St. Louis, MO, USA), L-glutamine (Gibco), Penicillin (100 units/ml) and Streptomycin (100 mg/ml) (both from Sigma), half of the culture medium was renewed every 2-3 days that coincides with monitoring the cells in terms of growth and morphological features via inverted microscope $[11,15]$.

\section{Collection of cerebrospinal fluid}

CSF was collected from 19-day-old Wistar rat embryos. In sterile conditions, CSF was collected from Cisterna magna region and transferred into sterile micro tubes. After centrifugation (14,000 rpm, 5 minutes, room temperature), the supernatant was kept in $-80^{\circ} \mathrm{C}$ temperature $[1,16,17]$.

\section{Neural differentiation induction}

Neurospheres formation of hDPSCs was performed as reported by Darabi et al. [18]. Briefly, $2 \times 10^{5}$ the hDPSCs cells were added on a 24 -well culture plate in medium containing serum-free DMEM/F12 with 5\% embryonic cerebrospi- 
nal fluid (E-CSF) for 2 days. Then, the neurospheres were cultured in the 6-well plate in DMEM/F12 supplemented with $10^{-6} \mathrm{RA}, 5 \% \mathrm{FBS}, 2 \% \mathrm{~B} 27,100 \mathrm{ng} / \mathrm{ml}$ glial-derived neurotrophic factor (GDNF, Invitrogen, Paisley, Scotland) and $200 \mathrm{ng} / \mathrm{ml} \mathrm{BDNF}$ (Invitrogen, Paisley, Scotland) for 6 days. In addition, $2 \times 10^{5}$ the hDPSCs cells were cultured on a $24-$ well culture plate in basic culture medium for 2 days, and then the neurosphers were transferred into the 6 -well plate in DMEM/F12 supplemented with 5\% FBS, 2\% B27, $100 \mathrm{ng} / \mathrm{ml}$ GDNF and $200 \mathrm{ng} / \mathrm{ml}$ BDNF for 6 days. The cells which were cultured in basic culture medium were considered as control group.

\section{Cell viability assay (MTT test)}

The cell metabolic activity of isolated hDPSCs quantitatively was assesed by the MTT (3-(4,5dimethylthiazol2-yl)-2,5-diphenyltetrazolium bromide) according to manufacturer instructions (Sigma-Aldrich). Briefly, hDPSCs were seeded $\left(4 \times 10^{4}\right.$ cells/well, in triplicate) in a 6-well plate. After incubation, under standard conditions of temperature and humidity, removed the supernatant and the cells were exposed to $50 \mu$ of Dimethyl sulfoxide (Sigma-Aldrich), then placed onto a roller for 5-10 minutes to dissolve the formazan crystals. Finally, the absorbance measured at $570 \mathrm{~nm}$ by a Cytofluor 4000 plate reader (PerSeptive Biosystems, Framingham, MA, USA) [19].

\section{Morphologic evaluation}

Morphologically differentiated cells were daily analyzed by inverted microscope (Eclipse-TS100; Nikon, Tokyo, Japan). In addition, the longest protrusion in each cell was considered as neurite out growth and the length of these processes was measured on days 4 and 8 after differentiation by Image J 1.41 software (National Institute of Health, Bethesda, MD, USA).

\section{Cytological evaluation}

Crystal violet stain: In order to identify Nissl bodies in neural-like cells, Cresyl violet (Cresyl Echt Violet Stain, Merck Germany) staining was performed on 8th day after induction. Cells were fixed in $4 \%$ paraformaldehyde (PFA, Sigma-Aldrich) for $20 \mathrm{~min}$ at room temperature and then washed three times with PBS, and stained using 0.5\% Cresyl violet for a period of 2-3 minutes and positive reaction cells were considered as neuron-like cells [4].

Bielschowsky's silver stain: After washing, the cells were incubated in solution that contains silver nitrate and ammoniacal silver nitrate for 15 minutes at $40^{\circ} \mathrm{C}$. Then, developer solution was used and the cell plates were washed in PBS. Dark brown-black neurites were considered as a positive reacted cells and axons length were measured using the software Image J 1.41 [10].

\section{Immunocytochemistry evaluation}

Expression of neuronal markers, Nestin and MAP2, was evaluated in differentiated cells using Immunocytochemistry. After three times washing with PBS, differentiated cells were fixed using $4 \%$ PFA. Then, the fixed cells were washed with PBS three times after 15 minutes. In the next step, to penetrate cells and inhibition of non-specific antigens, probably attached to secondary antibodies, they were incubated with Triton X-100 (Sigma-Aldrich) for 30 minutes and bovine serum albumin (BSA, Sigma-Aldrich) for 45 minutes at room temperature, respectively. Then, the cells were incubated for one hour with primary monoclonal antibodies. After three times washing with PBS, the cells were kept with suitable secondary antibodies conjugated with Phycoerythrin (PE, Sigma-Aldrich) for one hour at $37^{\circ} \mathrm{C}$. Then, DAPI (Sigma-Aldrich) was used for staining the nucleus. Finally, the neural markers were examined using fluorescent microscopes (Eclipse-TE600, Nikon) and imaging took place [20].

\section{Real-time polymerase chain reaction}

Total RNA was harvested from cell groups at different stages of cell differentiation using Trizol Reagent (Invitrogen Life Technologies, Carlsbad, CA, USA), after quantification,

Table 1. The sequences of the primers and conditions for real-time polymerase chain reaction

\begin{tabular}{|c|c|c|c|c|}
\hline Gene & Significance & Forward primer $\left(5^{\prime}-3^{\prime}\right)$ & Backward primer $\left(5^{\prime}-3^{\prime}\right)$ & Size (bp) \\
\hline Oct4 & Stemness marker & TATGCAAATCGGAGACCTG & AAGCTGATTGGCGATGTGAG & 143 \\
\hline Sox 2 & Stemness marker & CCGTTACAGACAAGGAAGG & CAACGATATCAACCTGCATG & 195 \\
\hline Nestin & Neuroprogenitor marker & AAGAGAGCATAGAGGCAGTAA & GAGATTTCAGTGTTTCCAGGT & 93 \\
\hline NF-M & Differentiating neuronal markers & GACGGCGCTGAAGGAAATC & CTTGGCGGAGCGGATGGCCT & 142 \\
\hline NF-H & Mature motor neuron marker & CAGCCAAGGTGAACACAGAC & GCTGCTGAATGGCTTCCT & 189 \\
\hline GAPDH & Internal control & GTTGTCTCCTGCGACTTCA & CTTAGAAGAGACGCAGAG & 190 \\
\hline
\end{tabular}



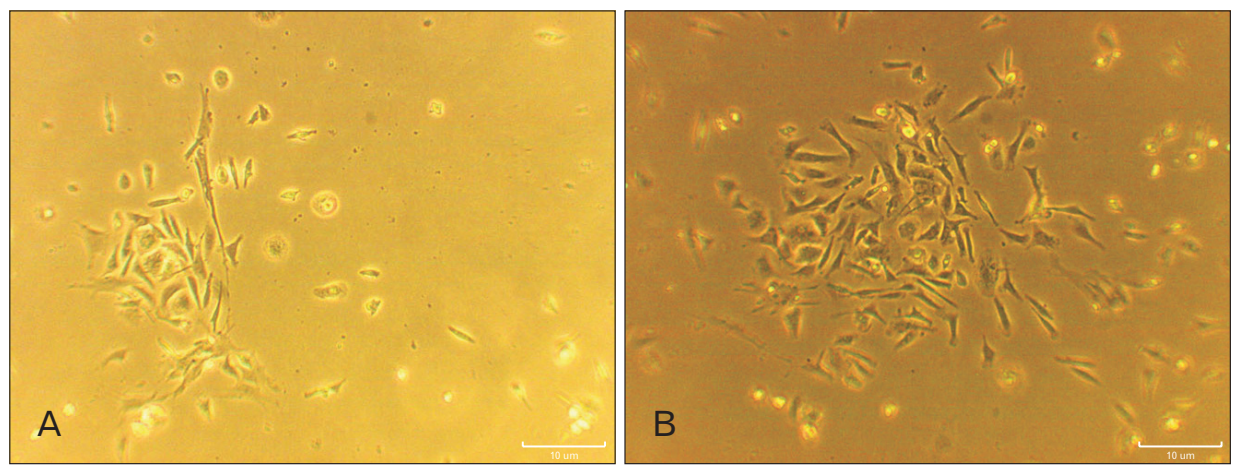

Fig. 1. Phase contrast microscopy photograph. (A) Fbroblast like cells of human dental pulp stem cells with spindleshaped morphology were observed. (B) Morphological modifications of human dental pulp stem cells 8 days after induction by the inverted microscope. Scale bars $=100 \mu \mathrm{m}(\mathrm{A}, \mathrm{B})$.

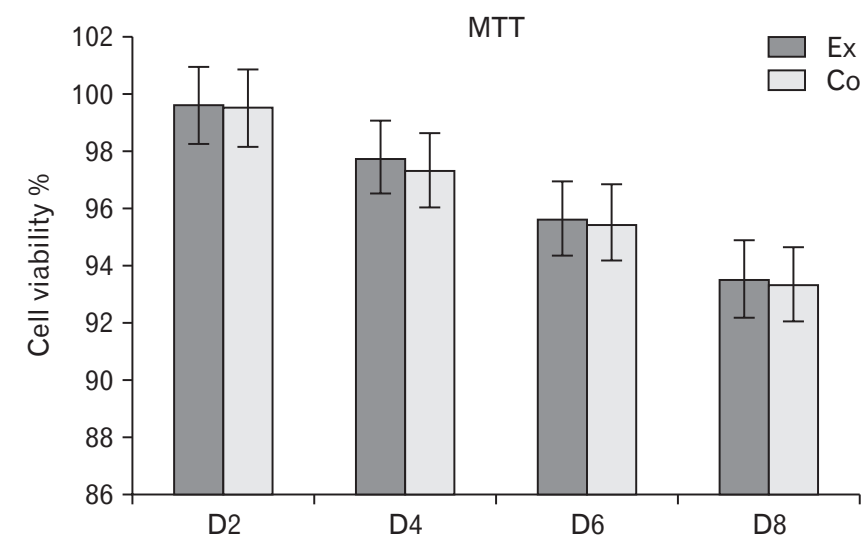

Fig. 2. The comparison between the mean viability rates at experimental and control groups in days (D) D2, D4, D6, and D8 $(P<0.05)$.

$5 \mu \mathrm{g}$ RNA was reverse-transcribed into cDNA using oligo dT primer and reverse transcriptase (Fermentas), according to the manufacturers' instructions. In this regard, random primers (Fermentas) were used, under standard conditions. Real-time polymerase chain reaction (PCR) amplifications were conducted for 3 minutes at $95^{\circ} \mathrm{C}$ and PCR cycling conditions were $95^{\circ} \mathrm{C}, 30$ seconds; $60^{\circ} \mathrm{C}, 45$ seconds; and $72^{\circ} \mathrm{C}$, 45 seconds; for 40 cycles and $72^{\circ} \mathrm{C}$ for 7 minutes for the final extension. For the real-time PCR analysis, the final products were separated on a $1.5 \%$ agarose gele (Fermentas) and detected with ethidium bromide, visualized and photographed on a UV transluminator. The sequence of the primers which are considered in this experiment are described in Table 1.

\section{Statistical analysis}

Statistical analysis was performed by SPSS for Windows, Version 16.0 (SPSS Inc., Chicago, IL, USA). One-way ANOVA and Chi Square test were used to analyze the data based on the comparison of the mean quantitative variables. In addition, significant level was considered as $P<0.05$.

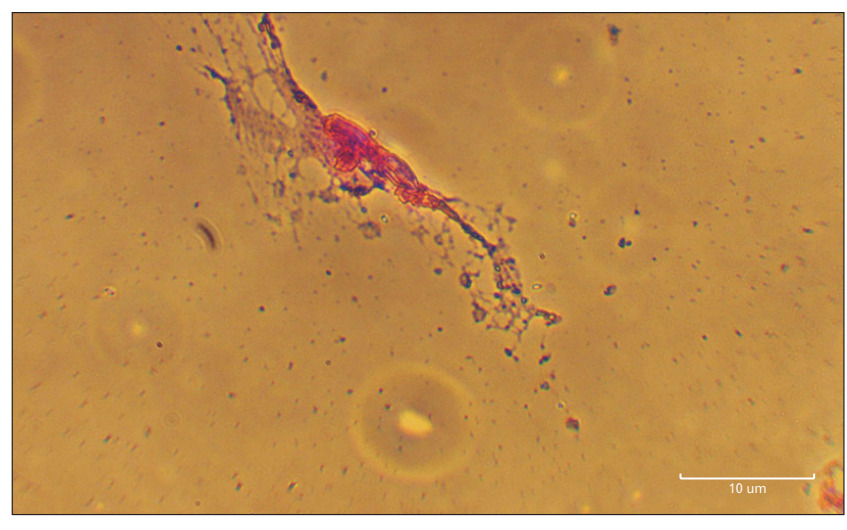

Fig. 3. Cresyl violet staining. Human dental pulp stem cells at experimental groups on day 8 . Scale bar $=10 \mu \mathrm{m}$.

\section{Results}

At the onset of cell culture, the hDPSCs were appeared elongated-shaped. The cells could be proliferated consistently and formed colony. Following, the cells were cultured and the sub-cultured cells exhibited fibroblast-like morphology and their phenotypes were kept during passages 3-5 (Fig. 1A).

Our morphological assay proved that specific neuronal morphological changes were observed with bipolar and multipolar soma, large euchromatin nuclear, clear nucleolus and a cytoplasm rich in granules in experimental group (Fig. 1B). It should be noticed that induced cells in some cases established their cytoplasmic processes and expanded synapses with adjacent cells. In addition, button like areas were found at the end point of cellular processes that may indicate the functional connection between neurons. These structures were only observed in treated group on day 8 (Fig. 1B). In contrast, cells which were cultured in basic culture medium, exhibited spindle-shaped fibroblast like-cell phenotype.

The percentages of viable cells in the experimental group in all days was higher than in the control group. However, 
there is not seen a significant differences between two groups $(P<0.05)$ (Fig. 2).

According to the results of Cresyl violet staining, the most of the neuron-like cells showed positive reaction. Moreover, spherical objects similar to Nissl bodies were found within the cytoplasm of these cells (Fig. 3).

One of the most important indicators of neuronal phenotype are presence of long process as axon in differentiated cells observed and were measurable in the treatment groups from 4th day (Fig. 4A, B). The diameter of processes with the same size or larger than cell body was measured in micrometer $(\mu \mathrm{m})$. The maximum length of axons was measured on day 8 in the experimental group compared to control group (Fig. 4C).

In order to identify neuroprogenitor cells and neuron-like cells, Nestin and MAP2 markers were applied, respectively. A high percentage of neural progenitors cells were detected in the experimental group. However, the expression of MAP2,
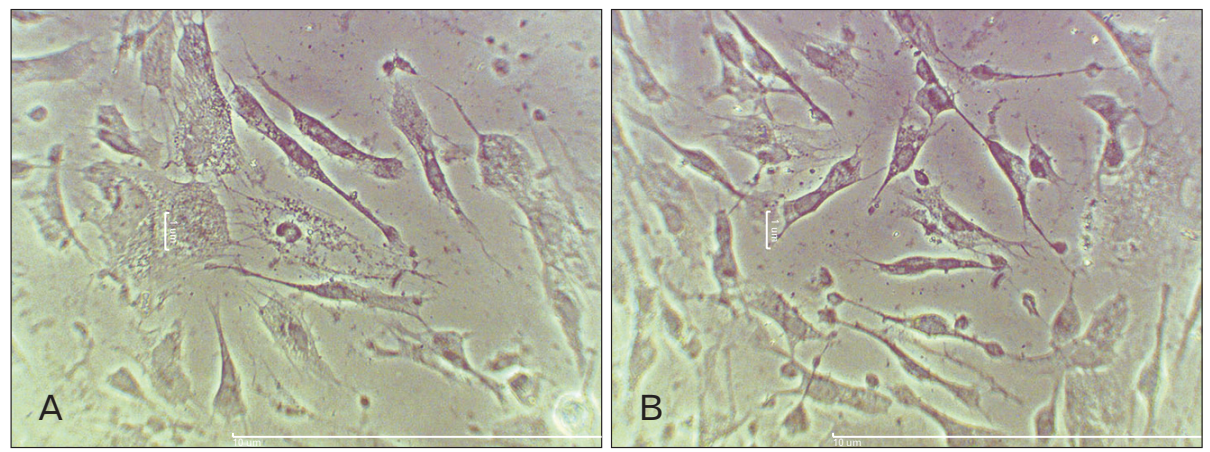

C

\begin{tabular}{lcc}
\hline & $\begin{array}{c}\text { Experimental } \\
\text { group }\end{array}$ & $\begin{array}{c}\text { Control } \\
\text { group }\end{array}$ \\
\hline Day 4 & 51.86 & 9.69 \\
Day 8 & 178.13 & 23.94 \\
\hline
\end{tabular}

Fig. 4. Bielschowsky's silver staining at experiment group in days $4(\mathrm{~A})$ and 8 (B) (Scale bars=10 $\mu \mathrm{m})$. (C) Comparing the rate of axon growth between the experimental group on days 4 and 8 with control group $(P<0.01)$.
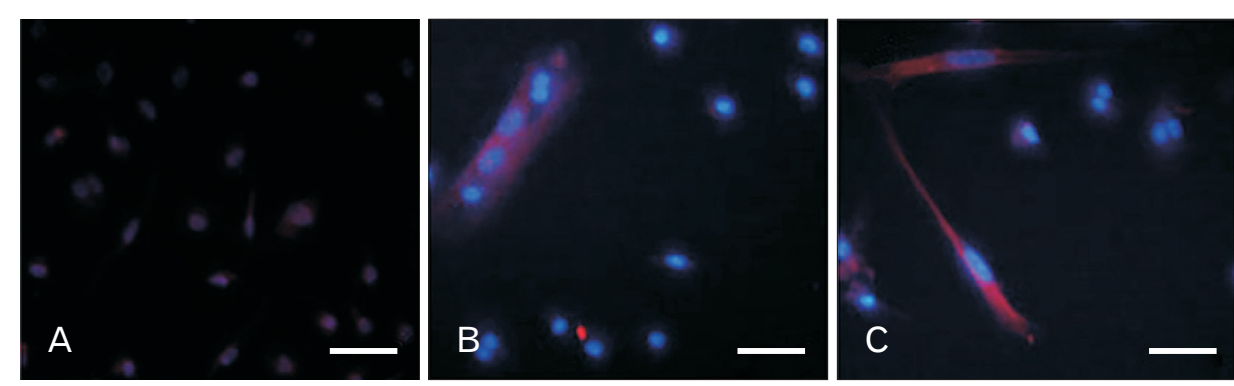

Fig. 5. Immunocytochemistry of neuronlike differentiated cells from human dental pulp stem cells. Expression of nestin the (A) control and (B) experimental groups on day $3,(C)$ expression of MAP2 in the experimental group on day 8 . Scale bars $=10 \mu \mathrm{m}(\mathrm{A}-\mathrm{C})$.

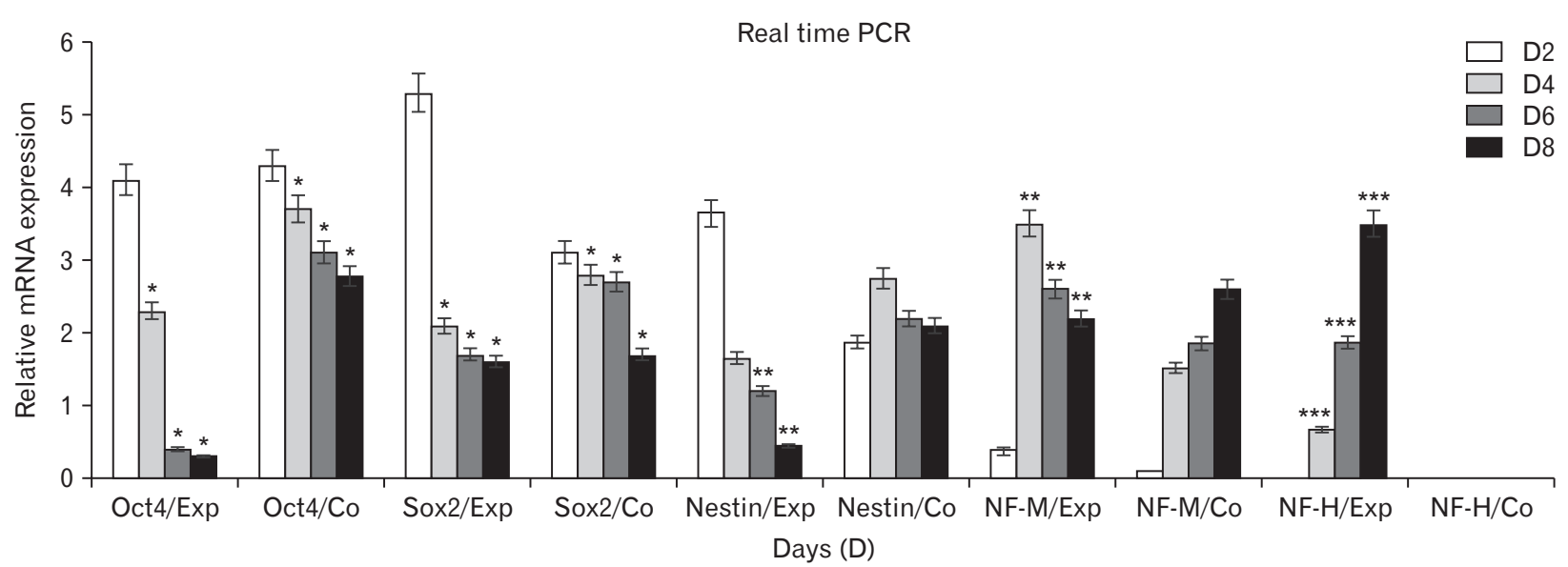

Fig. 6. Real-time polymerase chain reaction (PCR) analysis for neural markers during in vitro differentiation of human dental pulp stem cells $(\mathrm{n}=3$ biological samples, mean \pm standard deviation; ${ }^{*} P<0.05$, ${ }^{* *} P<0.01$, $\left.{ }^{* *} P<0.001\right)$. 
known as a marker for mature neurons, was only observed in the experimental group (Fig. 5).

Real-time PCR analysis revealed that higher expression of Oct 4 and Sox 2 (pluripotency genes) were seen at first day of neurospheres formation and their expresstion were remarkably decreased from day 4 to day 8 in experimental group than control group. However, the level of nestin expresstion was gradually increased from day 2 to day 4 in experimental group. Whereas, the expresstion NF-M was increased from day 4 to day 8 . In addition, the expresstion NF-H was not seen within first-two days of induction. Interestingly, their expression were considerably increased from day 4 to day 8 (Fig. 6).

\section{Discussion}

Neurodegenerative disease is the progressive disorder that causes the patient's disability and it imposes the high costs on patients and communities every year. Recently, the researchers sought to reveal the early pathogenic hallmark in $\mathrm{AD}$ and tried to block it [8]. In this way, they tried to prevent the death of neurons or progenitor neuron stem cells. But, the key point to consider is that the pathology of neurogical disorders begins long before the onset of clinical symptoms. So, without pre-clinic treatment, apoptosis is observed in neural progenitor stem cells and mature neurons before the appearance of cognitive symptoms [21]. Moreover, scientists have designed various therapeutic drugs, but unfortunately, the results have not been promising to replace the damaged neurons, they only relieve some of the physical or mental symptoms $[10,22]$. In contrast, stem cell therapy is one of the most important strategies in medicine [23,24]. One of the important factors to consider when choosing a cell source is the ability of cells to differentiate into the neuron-like cells in-vitro [24-26]. But most of these sources are obtained in invasive approaches [27]. Also, the efficiency of these differentiated cell is low and unpredictable [9]. Thus, in this study we used hDPSCs which are considered as a suitable cell source capable of neuronal differentiation. These cells derived from the ectomesenchymal neural crest, therefor they have biological characteristics of mesenchymal and neural crest stem cells that is similar to the origin of CNS [27]. In this regard, Zhang et al. [28] differentiated and transplanted these cells into the hippocampus of AD mice and observed higher repair ability compared with undifferentiated cells. In this study, for the first step, hDPSCs isolated and cultured and the real-time PCR analysis showed the expression of Oct 4 and Sox 2 that are related to pluripotency. In the next step, the process of cell differentiation of these clonical cells into neuron-like cells in neural culture media was considered [29]. As CSF is in direct contact with the stem cells niche of central nervous system, it seems that it contains factors such as growth and neurotrophic factors, cytokines, molecules binding extracellular matrix proteins and other nutrients required for survival, proliferation and differentiation of progenitor cells into mature neurons [30]. Considering the E-CSF have higher mean total protein concentration such as IGE- 2 and TGF- $\beta 3$ which is probably cause higher proliferation and more neural differentiation [1]. Also, E-CSF contains BMPs that cause to survival and phenotypic maturation of neuronal progenitor stem cells in developmental stages [17]. In this paper hDPSCs cultured with the medium supplemented with E-CSF, we hypothesized that adding E-CSF to the culture medium could provide a suitable molecules for differentiation of hDPSCs into neuron similar to a microenvironment provided in embryonic period. Also, in this study, the results showed that our treated cells survive in sequential passages without losing their ability to proliferate which is probably related to HGF/c-Met signaling that caused to development and maintenance of the nervous system [17], also, the results of MTT assay showed that the neuron-like cells viability after induction by E-CSF was significantly higher than control group. In healthy brain, the neurotransmitters travel across the synapse but, neurodegenerative disease destroys the way electrical charges travel whithin cells [31]. In current study, the differentiated cells in the treated group connect with each other through synaptic -like connections, which may serve as the functional properties of the differentiated cells. One possible explanation for this event is component of E-CSF such as memberanous particle that have an effect on the modulation of signal transduction [17]. Hence a profitable line of future research might be to confirm this evidence such as physiological monitoring. Furthermore, real-time PCR results illustrated the expression of Nestin gene as Neuroprogenitor marker in treated hDPSCs by E-CSF in the early days of the induction protocol. The result lend support to Lehtinen's study $[32,33]$. It seems that adding RA into the E-CSF containing medium leads to early differentiation of neural progenitor cells from hDPSCs. As well, it induces the proliferation of neural progenitor cell by IGF-2 that is just in E-CSF. In addition, CSF is able to induce final differentiation of neural precursor cells to ma- 
ture neurons by its neurotrophins [17]. At this point, realtime PCR showed the expression of NF-M and NF-H gene (respectively, as differentiating neural marker and mature motor neuron marker) at the end of the period of induction by E-CSF which confirms the results obtained through immunocytochemistry. The results of outgrowth measurement revealed that the highest growth of process -like neurite was seen in differentiated cells on day 8 with significant differences. This was attributed to the combination of RA and CSF which contains IL- $1 \beta$ and IL- 6 and Neurotrophins [17] which had synergistic effects on cells. The immunocytochemistry findings showed that, the percentage of Nestinexpressing cells in the treated group was higher than control group, this result supports the previous claims $[34,35]$. In the present study, the possible reasons for increasing the Nestinexpressing cells in the treated group compared to control group are that, CSF causes expression of genes such as Sonic hedgehog and transcription factors such as PAX6 and PAX7 related neurogenesis. These factors not only cause the initial differentiation of neural progenitor cells from hDPSCs, but also the proliferation of neural progenitor cells. It should be noted that a set of molecules such as BMP and Wnt interact in the induction of neuronal differentiation in vivo [36]. According to the results, presence of MAP2 expressing cells in treated group may be related to neurotrophic factors and other substances in the CSF that decreases the expression of the transcription factors and causes the transition from the pre-neural form and provides induction of adult neurons differentiation in culture medium. Furthermore, the morphological features of differentiated cells were demonstrated by cytological studies. Consistent with morphological assay, Nissl bodies were characterized with Cresyl violet stain as purple particles in the cytoplasm of cells and the percentage of positive reacted cells was significantly increased in induction and post-induction stages. Neurospheres these findings confirmed previous studies. Finally, further research investigating in vivo experiment would be a very useful follow-up to this study.

In conclusion, taking these together, we have designed a simple protocol for generating neuron-like cells using CSF from the hDPSCs, applicable for cell therapy in several neurodegenerative disorders.

\section{ORCID}

Ghazaleh Goudarzi: https://orcid.org/0000-0002-0421-1767

Hatef Ghasemi Hamidabadi:

https://orcid.org/0000-0002-2178-6503

Maryam Nazm Bojnordi:

https://orcid.org/0000-0003-1176-2417

Azim Hedayatpour:

https://orcid.org/0000-0002-1036-0697

Ali Niapour: https://orcid.org/0000-0002-9013-4664

Maria Zahiri: https://orcid.org/0000-0003-2978-0349

Forouzan Absalan:

https://orcid.org/0000-0002-7875-0173

Shahram Darabi: https://orcid.org/0000-0002-9405-6640

\section{Author Contributions}

Conceptualization: HGH. Data acquisition: GG, HGH. Data analysis or interpretation: MNB, AH, AN. Drafting of the manuscript: MZ, FA, SD. Critical revision of the manuscript: GG. Approval of the final version of the manuscript: all authors.

\section{Conflicts of Interest}

No potential conflict of interest relevant to this article was reported.

\section{Acknowledgements}

This project was funded by a grant from Mazandaran University of Medical Sciences, Sari, Iran (grant No. 1813).

\section{References}

1. Shokohi R, Nabiuni M, Irian S, Miyan JA. In vitro effects of wistar rat prenatal and postnatal cerebrospinal fluid on neural differentiation and proliferation of mesenchymal stromal cells derived from bone marrow. Cell J 2018;19:537-44.

2. Pandamooz S, Naji M, Alinezhad F, Zarghami A, Pourghasem $M$. The influence of cerebrospinal fluid on epidermal neural crest stem cells may pave the path for cell-based therapy. Stem Cell Res Ther 2013;4:84

3. Ren C, Yin P, Ren N, Wang Z, Wang J, Zhang C, Ge W, Geng D, Wang X. Cerebrospinal fluid-stem cell interactions may pave the path for cell-based therapy in neurological diseases. Stem Cell Res Ther 2018;9:66.

4. Goudarzi G, Hamidabadi HG, Abdanipour A, Kouchesfehani HM, Moghaddam AE. The influence of cerebrospinal fluid accompanied by retinoic acid on differentiation of bone marrow 
mesenchymal stem cells into neuron-like cells in vitro. Pathobiol Res 2016;18:79-91.

5. Ziegler AN, Levison SW, Wood TL. Insulin and IGF receptor signalling in neural-stem-cell homeostasis. Nat Rev Endocrinol 2015;11:161-70.

6. Lehtinen MK, Zappaterra MW, Chen X, Yang YJ, Hill AD, Lun M, Maynard T, Gonzalez D, Kim S, Ye P, D'Ercole AJ, Wong ET, LaMantia AS, Walsh CA. The cerebrospinal fluid provides a proliferative niche for neural progenitor cells. Neuron 2011;69:893-905.

7. Polanco JC, Li C, Bodea LG, Martinez-Marmol R, Meunier FA, Götz J. Amyloid- $\beta$ and tau complexity- towards improved biomarkers and targeted therapies. Nat Rev Neurol 2018;14:22-39.

8. Kondo A, Shahpasand K, Mannix R, Qiu J, Moncaster J, Chen $\mathrm{CH}$, Yao Y, Lin YM, Driver JA, Sun Y, Wei S, Luo ML, Albayram O, Huang P, Rotenberg A, Ryo A, Goldstein LE, Pascual-Leone A, McKee AC, Meehan W, Zhou XZ, Lu KP. Antibody against early driver of neurodegeneration cis P-tau blocks brain injury and tauopathy. Nature 2015;523:431-6.

9. Chang CC, Chang KC, Tsai SJ, Chang HH, Lin CP. Neurogenic differentiation of dental pulp stem cells to neuron-like cells in dopaminergic and motor neuronal inductive media. J Formos Med Assoc 2014;113:956-65.

10. Haratizadeh S, Nazm Bojnordi M, Darabi S, Karimi N, Naghikhani M, Ghasemi Hamidabadi H, Seifi M. Condition medium of cerebrospinal fluid and retinoic acid induces the transdifferentiation of human dental pulp stem cells into neuroglia and neural like cells. Anat Cell Biol 2017;50:107-14.

11. Bojnordi MN, Haratizadeh S, Darabi S, Hamidabadi HG. Neural derivation of human dental pulp stem cells via neurosphere technique. Bratisl Lek Listy 2018;119:550-3.

12. Bain G, Ray WJ, Yao M, Gottlieb DI. Retinoic acid promotes neural and represses mesodermal gene expression in mouse embryonic stem cells in culture. Biochem Biophys Res Commun 1996;223:691-4.

13. Nazm Bojnordi M, Movahedin M, Tiraihi T, Javan M, Ghasemi Hamidabadi H. Oligoprogenitor cells derived from spermatogonia stem cells improve remyelination in demyelination model. Mol Biotechnol 2014;56:387-93.

14. Sagha M, Esfandiari E, Razavi S, Tanhaee S, Nasr-Esfahani $\mathrm{MH}$, Baharvand $\mathrm{H}$. Role of retinoic acid in neural patterning of mouse embryonic stem cells. Arak Med Univ J 2013;16:16-26.

15. Mahmoudinia S, Niapour A, Ghasemi Hamidabadi H, Mazani M. 2,4-D causes oxidative stress induction and apoptosis in human dental pulp stem cells (hDPSCs). Environ Sci Pollut Res Int 2019;26:26170-83.

16. Gato A, Moro JA, Alonso MI, Bueno D, De La Mano A, Martín C. Embryonic cerebrospinal fluid regulates neuroepithelial survival, proliferation, and neurogenesis in chick embryos. Anat Rec A Discov Mol Cell Evol Biol 2005;284:475-84.

17. Nabiuni M, Shokohi R, Moghaddam P. CSF protein contents and their roles in brain development. Zahedan J Res Med Sci 2015; 17:e1042.

18. Darabi S, Tiraihi T, Delshad A, Sadeghizadeh M. A new mul- tistep induction protocol for the transdifferentiation of bone marrow stromal stem cells into GABAergic neuron-like cells. Iran Biomed J 2013;17:8-14.

19. Youssef AR, Emara R, Taher MM, Al-Allaf FA, Almalki M, Almasri MA, Siddiqui SS. Effects of mineral trioxide aggregate, calcium hydroxide, biodentine and Emdogain on osteogenesis, Odontogenesis, angiogenesis and cell viability of dental pulp stem cells. BMC Oral Health 2019;19:133.

20. Cao Q, Benton RL, Whittemore SR. Stem cell repair of central nervous system injury. J Neurosci Res 2002;68:501-10.

21. Fagan AM, Xiong C, Jasielec MS, Bateman RJ, Goate AM, Benzinger TL, Ghetti B, Martins RN, Masters CL, Mayeux R, Ringman JM, Rossor MN, Salloway S, Schofield PR, Sperling RA, Marcus D, Cairns NJ, Buckles VD, Ladenson JH, Morris JC, Holtzman DM. Longitudinal change in CSF biomarkers in autosomal-dominant Alzheimer's disease. Sci Transl Med 2014;6:226ra30.

22. Alipour M, Nabavi SM, Arab L, Vosough M, Pakdaman H, Ehsani E, Shahpasand K. Stem cell therapy in Alzheimer's disease: possible benefits and limiting drawbacks. Mol Biol Rep 2019;46:1425-46.

23. Gronthos S, Mankani M, Brahim J, Robey PG, Shi S. Postnatal human dental pulp stem cells (DPSCs) in vitro and in vivo. Proc Natl Acad Sci U S A 2000;97:13625-30.

24. Parr AM, Tator CH, Keating A. Bone marrow-derived mesenchymal stromal cells for the repair of central nervous system injury. Bone Marrow Transplant 2007;40:609-19.

25. Kim SH, Oh KW, Jin HK, Bae JS. Immune inflammatory modulation as a potential therapeutic strategy of stem cell therapy for ALS and neurodegenerative diseases. BMB Rep 2018;51:545-6.

26. Sanchez-Ramos JR. Neural cells derived from adult bone marrow and umbilical cord blood. J Neurosci Res 2002;69:880-93.

27. Wang F, Jia Y, Liu J, Zhai J, Cao N, Yue W, He H, Pei X. Dental pulp stem cells promote regeneration of damaged neuron cells on the cellular model of Alzheimer's disease. Cell Biol Int 2017;41:639-50.

28. Zhang W, Wang PJ, Sha HY, Ni J, Li MH, Gu GJ. Neural stem cell transplants improve cognitive function without altering amyloid pathology in an APP/PS1 double transgenic model of Alzheimer's disease. Mol Neurobiol 2014;50:423-37.

29. Hens J, Nuydens R, Geerts H, Senden NH, Van de Ven WJ, Roebroek AJ, van de Velde HJ, Ramaekers FC, Broers JL. Neuronal differentiation is accompanied by NSP-C expression. Cell Tissue Res 1998;292:229-37.

30. Chen Y, Teng FY, Tang BL. Coaxing bone marrow stromal mesenchymal stem cells towards neuronal differentiation: progress and uncertainties. Cell Mol Life Sci 2006;63:1649-57.

31. Reitz C, Brayne C, Mayeux R. Epidemiology of Alzheimer disease. Nat Rev Neurol 2011;7:137-52.

32. Haratizadeh S, Bojnordi MN, Niapour A, Bakhtiari M, Hamidabadi HG. Improvement of neuroglial differentiation from human dental pulp stem cells using CSF. Majallahi Danishgahi Ulumi Pizishkii Mazandaran 2016;26:1-14. 
33. Lehtinen MK, Bjornsson CS, Dymecki SM, Gilbertson RJ, Holtzman DM, Monuki ES. The choroid plexus and cerebrospinal fluid: emerging roles in development, disease, and therapy. J Neurosci 2013;33:17553-9.

34. Silvagno F, Guarnieri V, Capizzi A, Pescarmona GP. Synergistic effect of retinoic acid and dehydroepiandrosterone on differentiation of human neuroblastoma cells. FEBS Lett 2002;532:1538.

35. Yung SY, Gokhan S, Jurcsak J, Molero AE, Abrajano JJ, Mehler
MF. Differential modulation of BMP signaling promotes the elaboration of cerebral cortical GABAergic neurons or oligodendrocytes from a common sonic hedgehog-responsive ventral forebrain progenitor species. Proc Natl Acad Sci U S A 2002;99:16273-8.

36. Liu JP, Laufer E, Jessell TM. Assigning the positional identity of spinal motor neurons: rostrocaudal patterning of Hox-c expression by FGFs, Gdf11, and retinoids. Neuron 2001;32:9971012. 